\title{
Acil Servisimize Başvuran Hastaların 5 Yıllık Analizi
}

\section{5-Year Analysis of Patients Admitted to Our Emergency Department}

\author{
Ekrem Taha SERT ${ }^{1}$, Hüseyin MUTLU ${ }^{1}$, Kerim YEŞİIDAG ${ }^{2}$, Kamil KOKULU ${ }^{1}$, Ayhan SARITAŞ ${ }^{1}$ \\ ${ }^{1}$ Aksaray Üniversitesi, Tıp Fakültesi, Acil Tıp Kliniği, Aksaray \\ ${ }^{2}$ Konya Numune Hastanesi Göğüs Hastalıkları Bölümü, Konya
}

$\overline{\mathbf{O z}}$

Acil servise başvuran kritik hastalıkların özelliklerinin bilinmesi, en kısa sürede tanı alması ve doğru tedavilerinin başlamasında hayati öneme sahiptir Çalıșmamızda acil servise başvuran hastaların demografik ve klinik özelliklerini incelemeyi amaçladık. Ocak 2015 ile Aralık 2019 tarihleri arasında hastanemiz üçüncü basamak acil servisine başvuran tüm erişkin ve çocuk hastalar retrospektif olarak değerlendirildi. Hastaların demografik özellikleri, hastalık tanıları ve yıllara göre başvuru oranları değerlendirildi. Acile servise beş yıl içerisinde başvuran hasta sayıs1 2.254.302 olarak tespit edildi. Hastaların \%50.9'u erkek ve \%49.1'i kadındı ve yaş gruplarına göre başvuru sıklığı değerlendirildiğinden yoğun grubun \%26.73 ile 10 yaş ve altı olduğu görüldü. En çok başvuru \%51 ile 16:00-24:00 saatleri arasında idi. Hastaların en sik solunum sistemi problemleri $(\% 24,71)$ ile acile başvurduğu tespit edildi. Acil servise başvuran hastaların \%2.24'ü ilgili bölümlere, \%0.77'sinin ise yoğun bakım ünitesine yatırıldığ tespit edildi. Acil servislere başvuru oranının yüksek olması beraberinde aşırı hasta yoğunluğuna neden olmaktadır. Acil servise başvuran hasta profilinin belirlenmesi, verilecek hizmet sunumu ve hasta bakım kalitenin artırılmasında faydalı olacaktır.

Anahtar Kelimeler: Acil Servis, Demografik Özellikler, Hasta Profili, Hasta Sayısı

\section{Giriş}

Acil servisler günün 24 saati sağlık hizmeti veren ve her türlü acil tıbbi hizmetlerin verildiği en önemli birimlerdir (1).Bu nedenle hastalıkların çeşitliliği sınırsızdır. Acil servise başvuran kritik hastalıkların özelliklerinin bilinmesi, en kısa sürede tanı alması ve doğru tedavilerinin başlamasında hayati öneme sahiptir. Acil servisler tedavi gerektiren kritik hastaların bakıldığı yer olması gerekirken, acil olmayan ve basit-hafif şikayetleri olan hastaların başvurduğu birimler haline gelmiştir (2). Bu durum, sağlık hizmetinin kalitesini düşürerek ciddi hastalığı ve gerçek acil olan hastalara gösterilmesi gereken dikkat ve özenin azalmasına ve

\begin{tabular}{|c|c|}
\hline & ORCID No \\
\hline Ekrem Taha SERT & $0000-0002-7208-2186$ \\
\hline Hüseyin MUTLU & 0000-0002-1930-3293 \\
\hline Kerim YEŞİLDAĞ & 0000-0002-9151-4124 \\
\hline Kamil KOKULU & 0000-0002-6123-0898 \\
\hline Ayhan SARITAŞ & $0000-0002-4302-1093$ \\
\hline Başvuru Tarihi / Received: & 12.09 .2020 \\
\hline Kabul Tarihi / Accepted : & 07.01 .2021 \\
\hline Adres / Correspondence : & Hüseyin MUTLU \\
\hline \multicolumn{2}{|c|}{ Acil Tıp Kliniği, Aksaray Üniversitesi Tıp Fakültesi, Aksaray } \\
\hline e-posta / e-mail & hmutlu70@hotmail.com \\
\hline
\end{tabular}

\begin{abstract}
It is vital to know the characteristics of critical diseases admitted to the emergency department, to diagnose as soon as possible and to start the right treatment. In our study, we aimed to examine the demographic and clinical characteristics of the patients admitted to the emergency department. All adult and pediatric patients who admitted to the tertiary care emergency department of our hospital between January 2015 and December 2019 were evaluated retrospectively. The demographic characteristics of the patients, diagnoses and application rates according to the years were evaluated. The number of patients admitted to the emergency department within five years was $2,254,302.50 .9 \%$ of the patients were male and $49.1 \%$ were female. When the frequency of application was evaluated according to the age groups, it was seen that the most intense group was those aged 10 and below with $26.73 \%$. The highest application rate was between 4 p.m-12 p.m. with $26.73 \%$. It was found that the patients were admitted to the emergency department most frequently with respiratory system problems $(24.71 \%)$. It was determined that $2.24 \%$ of the patients admitted to the emergency department were hospitalized in the relevant wards and $0.77 \%$ were transferred to the intensive care unit. The high rate of admission to emergency departments also causes excessive patient density. Determining the patient profile that admitted to the emergency department will be useful in increasing the quality of service delivery and patientcare.

Keywords: Demographic Characteristics, Emergency Department, Number of Patients, Patient Profile
\end{abstract}

acil servis personelinin iş yükünü artırmasına neden olmaktadır $(3,4)$. Ayrıca ciddi hastalığı olan hastalarda müdahalede gecikmeye ve hasta memnuniyetinin azalmasına neden olmaktadır $(5,6)$.Özellikle ülkemizde diğer ülkelere oranla acil servislere çok fazla sayıda hasta başvurduğu bilinmektedir. Bunun nedeni acil servis tanımına uygun şekilde başvurunun yapılmaması ve acil servislerin birinci basamak sağlık birimleri gibi kullanılmasıdır.

Acil servislere başvuran hastaların sayısı, demografik özelliklerini, hastalıklara göre dağılımlarını ve acil serviste nasıl sonlandırıldıklarını belirleyerek, kaliteli acil sağlık hizmetinin neresinde olduğumuzu gösterebileceği düşünülmektedir. $\mathrm{Bu}$ nedenle çalışmamızda acil servise başvuran hastaların demografik ve klinik özelliklerini incelemeyi amaçladık.

\section{Gereç ve Yöntem}

Bu tanımlayıcı çalışmada 1 Ocak 2015 ile 31 Aralık 2019 tarihleri arasında hastanemiz üçüncü basamak acil servisine başvuran tüm erişkin ve çocuk hastalar değerlendirildi. Hastaların dosyaları retrospektif olarak taranarak veriler elde edildi. 
Çalışma Aksaray Üniversitesi Etik Kurulu'ndan izin alınarak yapılmıştır (22.06.2020, No:2020/06-69).

Hastaların demografik özelliklerine ait verilere (yaş ve cinsiyet dağılımları), başvuru zamanı (gün, ay ve saat), yıllara göre hasta sayıları ve triyaj kategorileri, hastaların tanı dağılımları ile acil servisten diğer servislere ve yoğun bakım ünitesine yatırılan hasta sayıları (yatış, taburcu, sevk) bilgisayar tabanlı hasta kayıt sistemi (Hastane Bilgi Yönetim Sistemi) kullanılarak ulaşıldı.

Çalışmadan elde edilen veriler, Microsoft Excel Çalışma programı kullanılarak analiz edilmiştir. Çalışma verileri değerlendirilirken tanımlayıcı istatistiksel yöntemleri (frekans (n) ve yüzde (\%) cinsinden) hesapland.

\section{Bulgular}

Beş yıllık süre içinde acil servise başvuran toplam 2.254.302 erişkin ve çocuk hastalar retrospektif olarak incelendi. Acil servise başvuru yapan hastaların; hastalık tanıları, yaş, cinsiyet, başvuru yılları, başvuru ayları ve başvuru saatleri baz alınarak değerlendirilmiştir. Cinsiyetlere göre dağ 1 lım incelendiğinde; \%50.9'u erkek, \%49.1'i kadın olduğu saptandı. Hastaların yaş gruplarına göre başvuru sıklığı incelendiğinde, 10 yaş ve altı grubun (\%26.73) en yüksek oranda olduğu görüldü. Bunu \%18.34 ile 20-29 yaş grubu izlerken, en az başvuru ise \%6.96 ile 50-59 yaş grubunda idi (Tablo 1).

Tablo 1. Hastaların yaş gruplarına göre dağılımı

\begin{tabular}{ccc}
\hline Yaş Grupları & Sayı $(\mathbf{n})$ & $\%$ \\
\hline$\leq 10$ yaş & 602.639 & 26,73 \\
$11-19$ yaş & 305.751 & 13,56 \\
$20-29$ yaş & 413.416 & 18,34 \\
$30-39$ yaş & 313.764 & 13,92 \\
$40-49$ yaş & 224.942 & 9,98 \\
$50-59$ yaş & 156.926 & 6,96 \\
$\geq 60$ yaş & 236.864 & 10,51 \\
Toplam & $\mathbf{2 . 2 5 4 . 3 0 2}$ & $\mathbf{1 0 0}$ \\
\hline
\end{tabular}

Acil servise başvuran hasta sayısı her y1l bir önceki yıla göre belirgin artış göstererek 532.450 başvuru ile 2019 yılında en fazla olduğu görülmektedir (Resim 1).

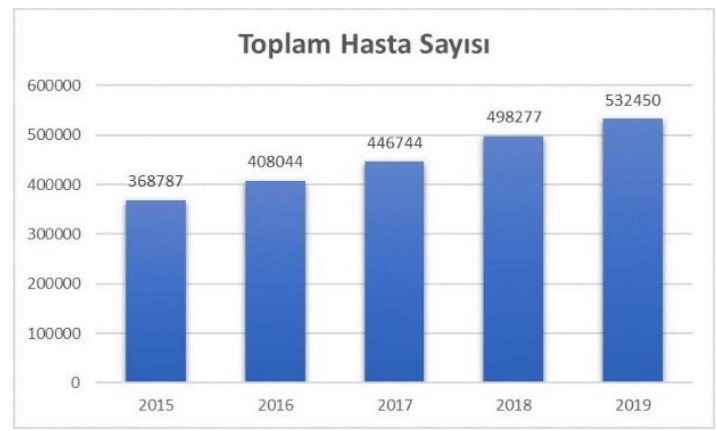

Resim 1. 2015-2019 yılları arasında Acil Servise başvuran hasta sayısı
Hastaların başvuruları saat aralıklarına göre değerlendirildiğinde, en çok başvurunun \%51 ile 16:00-24:00 saatleri arasinda olduğu gözlendi. 08:00-16:00 saatleri arasında başvuran hastaların oranı \%39, 00:00-08:00 saatleri arasinda bu oran $\% 10$ olarak tespit edildi (Resim 2).

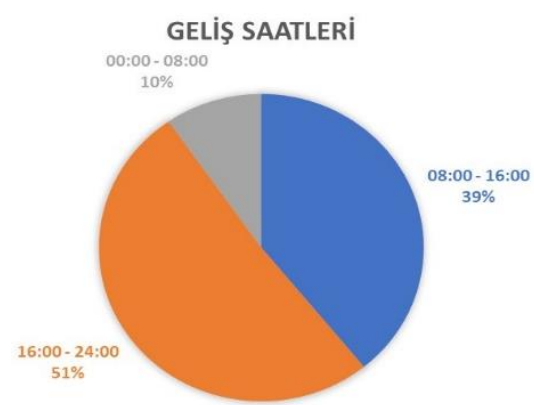

Resim 2. Hastaların Acil Servise başvurdukları zaman aralıkları

Hastaların triyaj kategorilerine bakıldığında \%79.7'sinin ( $\mathrm{n}=1.797 .224)$ yeşil (acil olmayan), $\% 20$ 'sinin $(n=450.160)$ triyaj sarı (acil), \%0.3'ünün $(n=6.918) \quad$ kırmızı (çok acil) şeklinde olduğu saptandı (Tablo 2). 2019 yılında yeşil alan hastasının $(n=410.307) 2015$ y1lına göre $(n=295.265) \% 6.4$ oranında arttığı tespit edildi. Aylara göre başvuru oranlarına bakıldığında, 2015 yılında en çok Mart ayında, 2016'da Ocak, 2017'de Ocak, 2018'de Ağustos ve 2019'da ise Aralık ayı olduğunu tespit ettik (Tablo 3). Hastalık gruplarına göre hastaların dağılımı incelendiğinde; en sık solunum sistemi problemleri (\%24.71) olduğu görüldü. Bunu kas/iskelet sistemi problemleri (\%17.46) ve kardiyovasküler problemler $(\% 14,55)$ izledi (Tablo 4). Hastalarımızın \%2.24'ünün $(n=50.617)$ ilgili klinik servislere yatmıș olduğu,\%0.77'si (n=17.413) yoğun bakım ünitesine yatışlarının yapıldığı tespit edildi (Tablo 5). 2018 yılında diğer yıllara göre acil servis den yoğun bakım ünitesi yatırılan hasta sayısının daha fazla olduğu görülmektedir. Sevk edilen hasta sayımız 2015 yılında 619, 2016 yılında 741, 2017 yılında 553, 2018 y1lında 471, 2019 yılında ise $375^{\prime}$ dir.

\section{Tartışma}

Acil servisler, kritik hastalara zamanında gerekli tıbbi müdahale ve bakımın yapıldı ̆̆ 1 sağlık birimleridir. Artan nüfusa ve sağllk hizmetlerine erişimin kolaylaşmasına paralel olarak hastaların acil servise başvurularında da artış olmaktadır (7). Artan bu yoğunluk içindeki acil servis hizmetlerinin hızlı, doğru ve kesintisiz olması için acil servislerin tanımına uygun olarak hizmet vermesi önemlilik arz etmektedir. $\mathrm{Bu}$ nedenle acil servislere başvuran hastaların sayı ve özelliklerinin bilinmesi acil servislerde nasıl bir hizmet verileceğini belirlenmesi açısından oldukça önemlidir. 
Tablo 2. Triyaj renk kodları açısından hastaların yıllara göre dağılımı

\begin{tabular}{cllllll}
\hline Triyaj Renk Kodları & $\mathbf{2 0 1 5}$ & $\mathbf{2 0 1 6}$ & $\mathbf{2 0 1 7}$ & $\mathbf{2 0 1 8}$ & $\mathbf{2 0 1 9}$ & Toplam \\
\hline Yeșil & 295.265 & 336.778 & 361.966 & 392.908 & 410.307 & 1.797 .224 \\
Sarı & 72.136 & 68.624 & 83.532 & 104.428 & 121.440 & 450.160 \\
Kırmızı & 2.386 & 1.692 & 1.246 & 941 & 653 & 6.918 \\
\hline
\end{tabular}

Tablo 3. Hasta başvurularının aylara göre dağılımı

\begin{tabular}{|c|c|c|c|c|c|c|c|c|c|c|}
\hline \multirow[t]{2}{*}{ Aylar } & \multicolumn{2}{|c|}{2015} & \multicolumn{4}{|c|}{$\begin{array}{l}\text { Yillar } \\
2017\end{array}$} & \multicolumn{2}{|c|}{2018} & \multicolumn{2}{|c|}{2019} \\
\hline & $\mathbf{N}$ & $\%$ & $\mathbf{N}$ & $\%$ & $\mathbf{N}$ & $\%$ & $\mathbf{N}$ & $\%$ & $\mathbf{N}$ & $\%$ \\
\hline Ocak & 26.388 & 7.16 & 45.153 & 11.07 & 42.159 & 9.44 & 39.474 & 7.92 & 41.551 & 7.80 \\
\hline Şubat & 25.582 & 6.94 & 28.972 & 7.10 & 32.861 & 7.36 & 35.979 & 7.22 & 34.922 & 6.56 \\
\hline Mart & 34.975 & 9.48 & 32.790 & 8.04 & 36.449 & 8.16 & 43.725 & 8.78 & 46.697 & 8.77 \\
\hline Nisan & 30.935 & 8.39 & 31.416 & 7.70 & 32.950 & 7.38 & 40.308 & 8.09 & 46.314 & 8.70 \\
\hline Mayıs & 29.662 & 8.04 & 32.107 & 7.87 & 34.242 & 7.66 & 39.582 & 7.94 & 37.654 & 7.07 \\
\hline Haziran & 25.928 & 7.03 & 28.589 & 7.01 & 30.697 & 6.87 & 38.323 & 7.69 & 42.199 & 7.93 \\
\hline Temmuz & 33.101 & 8.98 & 36.819 & 9.02 & 38.188 & 8.55 & 43.773 & 8.78 & 43.235 & 8.12 \\
\hline A ğustos & 34.832 & 9.45 & 37.274 & 9.13 & 42.982 & 9.62 & 52.498 & 10.54 & 49.066 & 9.22 \\
\hline Eylül & 32.097 & 8.70 & 35.685 & 8.75 & 41.926 & 9.38 & 41.188 & 8.27 & 45.836 & 8.61 \\
\hline Ekim & 32.448 & 8.80 & 35.579 & 8.72 & 39.845 & 8.92 & 42.176 & 8.46 & 47.137 & 8.85 \\
\hline Kasım & 30.129 & 8.17 & 30.941 & 7.58 & 33.822 & 7.57 & 36.555 & 7.34 & 43.372 & 8.15 \\
\hline Aralık & 32.710 & 8.87 & 32.719 & 8.02 & 40.623 & 9.09 & 44.696 & 8.97 & 54.467 & 10.23 \\
\hline
\end{tabular}

Tablo 4. Hastalık gruplarına göre hastaların dağılımı

\begin{tabular}{lcc}
\hline Hastalık Grupları & Hasta Sayısı (n) & \% \\
\hline Kardiyovasküler S. & 328.076 & 14.55 \\
Travma & 137.565 & 6.1 \\
Solunum S. & 557.076 & 24.71 \\
Nörolojik & 64.100 & 2.84 \\
GİS & 236.993 & 10.51 \\
Enfeksiyon Hst. & 34.414 & 1.53 \\
Kas-İskelet S. & 393.667 & 17.46 \\
Üriner S. & 58.733 & 2.61 \\
Jinekolojik-Obstetrik S. & 21.708 & 0.96 \\
Endokrin-Metabolik Hst. & 25.437 & 1.13 \\
Psikiyatrik Hst. & 18.686 & 0.83 \\
Zehirlenmeler & 1.618 & 0.07 \\
Allerji Hst. & 77.048 & 3.42 \\
Yenidoğan & 12.953 & 0.57 \\
Hematolojik-Onkolojik Hst. & 3.971 & 0.18 \\
Göz Hst. & 1.541 & 0.07 \\
KBB & 225.401 & 9.99 \\
Diğer & 55.315 & 2.45 \\
\hline
\end{tabular}

Tablo 5. Servisler ve Yoğun Bakım Ünitesine yatırılan hastaların yıllara göre dağılımı

\begin{tabular}{lcccccc}
\hline & $\mathbf{2 0 1 5}$ & $\mathbf{2 0 1 6}$ & $\mathbf{2 0 1 7}$ & $\mathbf{2 0 1 8}$ & $\mathbf{2 0 1 9}$ & Toplam \\
\hline Servis & 9.565 & 8.287 & 8.624 & 10.193 & 13.948 & 50.617 \\
Yoğun Bakım Ünitesi & 3.034 & 3.521 & 3.642 & 3.770 & 3.446 & 17.413 \\
\hline
\end{tabular}

Acil servise başvuran hastalarla ilgili yapılan bazı çalışmada kadınların acil servislere daha fazla başvurduğu tespit edilmiştir $(5,6)$. Çalışmamızda ise erkeklerin $(\% 50.9)$ oranı kadınların oranı ile $(\% 49.1)$ hemen hemen eşit olduğu görülmüştür. Köse ve ark. Yaptıkları çalışmada acile başvuran hastaların \%77'sinin 17-65 yaş arasında, \%14.7'ü 1-16 yaş arasında, \%7.1'i ise 65 yaş ve üzeri olduğu görülmüştür (8). Başka bir çalışmaya göre, acil servise başvuran hastaların \%24.6'sı 14-30 yaş arası, \%13'ü 31-40 yaş arası, \%16.2'si 41-50 yaş arası ve $\% 41$ 'i ise 50 yaş ve üstü hastalar olduğu tespit 
edilmiștir (1). Çalışmamızdaki hastaların yaş gruplarına göre dağılımı değerlendirildiğinde, diğer çalışmalardan farklı olarak en yoğun grubun $\% 26.73$ ile 10 yaş ve altı olduğu görüldü. Bunu \%18.34 ile 20-29 yaş grubu izledi. Hasta tanılarıyla beraber incelendiğinde 10 yaş ve altı grubundaki bu farklılığın nedeninin ebeveynlerin çocuklarla ilgili her türlü yakınmayı acil olarak algılaması nedeniyle acil müdahale gerektirmeyen şikayetler için de acil servise başvurmalarına bağlı olabileceği düşünülmüştür.

Çalışmamızda hastaların en çok başvuru saatinin 16:00-24:00 (\%51) arasında olduğu gözlendi. 08:0016:00 saatleri arasinda \%39, 00:08:00 saatleri arasında bu oran \%10 idi. Aydın ve ark. (9) yaptıkları çalışmada hastaların \%53.3'ününacil servise başvuru saatinin 08:00-16:00 arasında olduğu, Sucu ve ark. (10) çalışmasında hastaların \%45.3'ünün acil servise başvuru saatinin 12.0018.00 arasında olduğu belirlenmiştir. Bizim çalışmadaki acil servisi başvuran hasta sayısı mesai saatleri dışında daha da artmaktadır. İnsanların işlerinden döndükten sonra acile başvurmaları ve normal poliklinik hizmetlerine göre tetkik-tedavi işlemlerinin daha hızlı yapılması bu yoğunluğun nedenleri olabileceğini düşünmekteyiz.

Beş yıllık süre içinde hastalık gruplarına göre hastaların dağılımları incelendiğinde, sıklık sırasına göre, \%24.71'i (557.076) solunum sistemi, $\% 17.46$ 's1 ( $\mathrm{n}=393.667)$ kas/iskelet sistemi, \%14.55'i $(\mathrm{n}=328.076) \quad$ kardiyovasküler, $\% 10.51$ 'i $(n=236.993)$ gastrointestinal problemlerin izlediği tespit edilmiştir. Görüldüğü üzere hastaların tanıları değerlendirildiğinde solunum sistemi problemleri ile başvuran hastalar ilk sıralarda yer almaktadır. Bu da acil servise yapılan başvuruların özellikleri hakkında bir fikir vermektedir.

Triyaj kategorileri incelendiğinde, acil servise başvuran hastaların \%79.7'sinin yeşil (acil olmayan), \%20'si sarı (acil), \%0.3'ünün kırmızı (çok acil) şeklinde sınıflandırıldığı tespit ettik. Yıllara göre triyaj kategorileri incelendiğinde, 2019 yılında yeşil (acil olmayan) alan başvurularında artış gözlenirken, kırmızı (çok acil) alan başvurularda diğer y1llara göre azalma olduğu tespit ettik. Oktay ve ark. (6) çalışmalarında; kategorilendirme ve hekim kararları sonrasında, başvuruların \%31.2'sinin acile başvuru için uygun olmadığını göstermişlerdir. Başka bir çalışmaya göre acil servislerin uygunsuz kullanımının \%5-82 arasında değiştiğini belirtmektedir (11).Kılıçaslan ve ark. (12) bir üniversite hastanesinde yaptıkları çalıșmada acil olmayan hastaların oranı \%47.24 olarak belirtmiş. Aynı çalışmada hastaların hastaneye yatış oranı \%12 olarak bulunmuştur. Diğer bir çalışmada ise acil servisten diğer servislere yatış oranları \%11.9 olarak tespit edilmiştir (13). Yapılmış birçok çalışmada acil servislerden taburculuk oranlarının \%81-87 arasında olduğu görülmüştür $(9,12,14)$.
Çalışmamızda beș yıllık süreçte hastaların \%96.99'u acil servisten ayaktan taburcu edilirken, \%2.24'ü ilgili bölümlere, \%0.77'si yoğun bakım ünitesine yatışının yapıldığı tespit edildi. Buna göre başvuran hastaların büyük çoğunluğunun acil servis tanımına uygun olmadığını tespit ettik.

Sonuç olarak, acil servisler multidisipliner yaklaşım ve acil müdahale gerektiren birçok hastanın değerlendirildiği önemli birimlerdir. Hasta yoğunluğu ve acil servislere yapılan başvuruların fazlalığı nedeniyle sağlık durumu daha ciddi olan hastalara verilmesi gereken özen ve dikkatin azalmasına neden olmaktadır. $\mathrm{Bu}$ nedenle acile başvuran hastaların sayı ve niteliğinin bilinmesi acil servislerde verilecek hizmeti belirlemek bakımından oldukça önemlidir.

Etik Kurul Onayı: Aksaray Üniversitesi Etik Kurulu'ndan 22.06.2020 tarih ve 2020/06-69 nolu yazı ile izin alınmıştır.

\section{Kaynaklar}

1. Polat O, Kabaçam G, Güler İ, Ergişi K, Yıldız A. İbn-i Sina Hastanesi Acil Servis'ne başvuran hastaların sürveyans analizi. Türkiye Acil Tıp Derg. 2005;5(2):78-81.

2. Ersel M, Karcıoğlu Ö, Yanturalı S, ve ark. Bir acil servisin kullanım özellikleri ve bașuran hastaların aciliyetinin hekim ve hasta açısından değerlendirilmesi. Türkiye Acil Tıp Derg. 2006;6(1):25-35

3. Coleman P, Irons R, Nicholl J. Will alternative immediate care services reduce demands for non-urgent treatment at accident and emergency? Emerg Med J. 2001;18(6):482-7.

4. Eroglu SE, Toprak SN, Urgan O, et al. Evaluation of nonurgent visits to a busy urban emergency department. Saudi Med J. 2012;33(9):967-72

5. Edirne T, Edirne Y, Atmaca B, Keskin S. Yüzüncü Yıl Üniversitesi Tıp Fakültesi Acil Servis hastalarının özellikleri. Van Tip Derg. 2008;15(4):107-11

6. Oktay C, Cete Y, Eray O, Pekdemir M, Gunerli A. Appropriateness of emergency department visits in a Turkish university hospital. Croa tMed J. 2003;44(5):585-91.

7. Herring, AA, Ginde AA, Fahimi J, et al. Increasing critical care admissions from U.S. emergency departments, 20012009.Crit Care Med. 2013;41(5):1197-204

8. Köse A, Köse B, Öncü MR, Fuzuli T. Bir devlet hastanesi acil servisine başvuran hastaların profili ve başvurunun uygunluğu. Gaziantep T1p Derg. 2011;17(2): 57-62.

9. Aydın T, Aydın ŞA, Köksal Ö, ve ark. Uludağ Üniversitesi Tıp Fakültesi Hastanesi Acil Servisi'ne başvuran hastaların özelliklerinin ve acil servis çalışmalarının değerlendirilmesi. Akademik Acil Tıp Derg. 2010:9(4):163-8

10. Sucu G, Cebeci F, Karazeybek E. Acil servisteki kritik hasta yakınlarının gereksinimleri ve karşılanma durumu. Ulusal Travma Acil Cerrahi Derg. 2009;15(5):473-81.

11. Gill JM. Non urgent use of the emergency department: Appropriate or not? Ann Emerg Med.1994; 24(5):953-7.

12. Kılıçaslan İ, Bozan H, Oktay C, Göksu E. Türkiye'de acil servise başvuran hastaların demografik özellikleri. Türkiye Acil Tip Derg. 2005;5(1):5-13.

13. Kurtoğlu Celik G, Karakayalı O, Temrel TA, et al. Evaluatıon Of Patıents Transported To The Emergency Department By 112. Turkish Med J. 2012;6(3):73-6.

14. Karakaya Z, Gökel Y, Açıkalın A, Karakaya O. Acil Tıp Anabilim dalında konsültasyon sisteminin ișleyiși ve etkinliğinin değerlendirilmesi. Ulus Travma Acil Cerrahi Derg. 2009;15(3):210 